\title{
Effects of stress controllability, immunization, and therapy on the subsequent defeat of colony intruders
}

\author{
JON L. WILLIAMS and DEAN M. LIERLE \\ Kenyon College, Gambier, Ohio
}

\begin{abstract}
Three experiments investigated the influence that various stress-controllability manipulations had on the defensive behaviors of rats when they were subsequently tested as intruders in previously established, aggressive colonies of conspecifics. In Experiment 1, naive subjects that had received a session of 80 shocks in a tube showed an enhanced series of defensive responses and received more bites than did a group of restrained nonshocked rats as colony intruders $24 \mathrm{~h}$ later. These two measures were also found to be positively correlated within each group. In Experiment 2, a group that was given 80 yoked inescapable shocks, in contrast to a group that had wheelturn escape training and a restrained nonshocked control group, displayed more defeat and was bitten more frequently when tested as intruders on the following day. In Experiment 3,60 trials of wheel-turn escape training were given $4 \mathrm{~h}$ prior to (i.e., immunization) or after (i.e., therapy) a session of 60 inescapable tube shocks. During resident-intruder testing $24 \mathrm{~h}$ later, both of these groups showed less defeat and received fewer bites than did an inescapably preshocked group but did not differ from a restrained nonshocked control group. These findings clearly indicate that stress controllability alters species-typical defensive responses, and their implications concerning other learned helplessness effects and interpretations are discussed.
\end{abstract}

To a large degree, an organism's inability to deal with a stressor by means of some response is critical in determining whether behavioral and physiological disturbances will be subsequently manifested. In rats and mice, uncontrollable shock, in contrast to controllable shock, results in such behavioral changes as deficits in escape performance, an inability to form response-outcome associations involving choice, and reductions in unlearned activity and exploration (see Maier et al., 1983, for a current review of this literature). Uncontrollable, as opposed to controllable, shock also produces a number of physiological disruptions, such as an alteration in the availability and utilization of various neurotransmitters (Anisman, Kokkinidis, \& Sklar, 1982; Weiss et al., 1981) and an antinociceptive reaction to pain which interacts with exogenous morphine analgesia and withdrawal (see Maier et al., 1983; Williams, Drugan, \& Maier, 1984, for relevant reviews).

Related to the aforementioned alterations in behavior and physiology, a number of investigators have claimed that aversive events, along with associated conditioned and unconditioned stimuli, result in fear as a central motivational state (e.g., D. C. Blanchard, \& R. J. Blanchard, 1984a; Bolles, 1972; Fanselow \& Lester, 1986).

This research was supported by USPHS Research Grant 1 RD3MH38528-01 to the senior author. The authors wish to thank Charles Rice and Kenneth King for their helpful comments. Reprint requests should be addressed to Jon L. Wiliams, Department of Psychology, Kenyon College, Gambier, OH 43022.
Fear is assumed to restrict an animal's behavior to its repertoire or hierarchy of species-specific defense reactions (Bolles, 1970) and to suppress the activity of other motivational systems. A rat may freeze (e.g., Fanselow \& Baackes, 1982), flee (N. E. Miller, 1948), or even bury the feared stimulus (Pinel \& Treit, 1978). The particular defense response that the rat makes is determined by the physical dimensions and contextual cues of the test environment as well as by the experience that the animal has had in dealing with the specific stressor, or a similar one, in the past (R. J. Blanchard \& D. C. Blanchard, 1981). An important assumption pertaining to this type of ethological interpretation is that aversive stimulation is not linked directly to one specific response. Rather, fear activates a defense or submission system (Adams, 1980), which facilitates some defensive behaviors while suppressing others.

Of particular relevance to the present series of experiments are findings that indicate that inescapable shock influences unlearned agonistic behaviors. Several studies have demonstrated that inescapable shock decreases subsequent shock-elicited fighting between pairs of rats (e.g., Anderson, Crowell, Wikoff, \& Lupo, 1980; Maier, Anderson, \& Lieberman, 1972). However, R. J. Blanchard and his colleagues have argued convincingly that shockelicited fighting represents a mixture of shock-elicited movement and defensive boxing (D. C. Blanchard \& R. J. Blanchard, 1984b). Using a food-competition paradigm, Rapaport and Maier (1978) found that among rats given inescapable shock, escapable shock, or restraint without shock, the rats given inescapable shock were the only ones 
to show a later reduction in dominance. $R$. J. Blanchard and D. C. Blanchard (1977) and Williams (1982), however, have seriously questioned whether this type of task is a valid measure of agonistic behavior, since it elicits no specific species-typical aggressive or defensive responses. These investigators have suggested that the most useful and informative method for investigating offensive and defensive response patterns in the rat is the colonyintruder paradigm. In this situation, attack responses (e.g., lateral attack, being on top of a conspecific, biting) are usually made only by a single dominant-male colony resident. In contrast, the colony intruder typically displays a series of defensive responses (e.g., defensive boxing, lying on its back), which often enables it to protect its back from being bitten by the alpha resident male (R. J. Blanchard, Takahashi, \& D. C. Blanchard, 1977). What is important, from an evolutionary perspective, is that the topographies of these offensive and defensive responses are also observed in wild rats, and to some degree, in mice during laboratory and naturalistic resident-intruder encounters (R. J. Blanchard \& D. C. Blanchard, 1981).

A few studies using a colony-intruder model have shown that shock, like defeat from a conspecific (Leshner, 1981 ) or the presence of a predator (R. J. Blanchard, Kleinschmidt, Flannelly, \& D. C. Blanchard, 1984), can completely abolish offensive attack and increase defensive responding. However, only one colony-intruder study has specifically examined the effects of shock controllability on agonistic responses. Williams (1982) demonstrated that inescapably shocked dominant males later showed virtually no aggressive, or offensive, behavior and an increase in defensive responding when they later encountered an intruder in their colonies. In contrast, there was no change in either offensive or defensive behaviors of alpha rats that had escapable shock or were simply restrained without shock. Furthermore, the male partners (i.e., subordinate colony residents) of the inescapably shocked alpha animals became more aggressive and less defensive in response to the decline in dominance of their alpha partners. These results clearly indicate that inescapable shock, but not escapable shock, reduces offensive aggression and increases defense in dominant males. Such changes were also found to influence the complex nature of agonistic encounters within the colony, rapidly resulting in a striking shift in social dominance.

The major objective of the present series of experiments was to examine the effects of inescapable shock and shock controllability on isolated animals that were later to be tested as intruders in aggressive colonies. On the basis of findings that inescapable shock seems to activate a defensive mode of responding, it was hypothesized that such shocks would potentiate the defeat displayed by these intruders. The primary reason that this research focused on the behavior of intruders was that their experimental history, involving conspecific isolation before shock exposure, parallels that of subjects used in most studies dealing with the effects of inescapable shock (e.g., learned helplessness experiments). Perhaps the previously men- tioned alterations in behavior and physiology produced by inescapable shock would also be accompanied or mediated by a fear-defense system involving species-typical responses. Examining the effects of inescapable shock and shock controllability on the subsequent defeat of isolated, cage-housed intruders would provide illuminating evidence regarding this possibility.

\section{EXPERIMENT 1}

Assuming that uncontrollable shock enhances fear and defense, the purpose of this experiment was to ascertain whether exposure to inescapable shock would potentiate the degree of defeat shown by such rats when they were later tested as intruders in colonies known to have aggressive males. The procedural manipulations used to provide the stressful experience were identical to those employed by Maier and his colleagues (e.g., Maier, Albin, \& Testa, 1973; Maier \& Jackson, 1979) in experiments demonstrating the symptoms of learned helplessness. In short, a group of stressed rats received a series of brief inescapable tailshocks while being restrained in a tube. Comparable restraint experience was given to a control group which did not receive shocks. On the next day, both groups were given a few priming shocks in the tube before being tested as intruders in previously established colonies with aggressive dominant males. The purpose of the priming shocks was to reinstate the stress reactions experienced by the preshocked animals (see Maier et al., 1973, and Maier, Coon, McDaniel, Jackson, \& Grau, 1979 , for a more complete rationale for using priming shocks when behavioral or physiological testing is administered $24 \mathrm{~h}$ after the preshock treatment). Although priming shocks were not used by Williams (1982) in assessing the decrease in offensive attack by inescapably shocked alpha males, such shocks were considered to be more critical in attempting to enhance defeat in rats that had had no experience with conspecific fighting. In many respects, the present subjects had had the same experience as most subjects in learned helplessness studies which typically are given priming shocks before testing. The measures of intruder defeat recorded during the residentintruder test, following the priming shocks, were similar to the defensive behaviors described by R. J. Blanchard and D. C. Blanchard (1977) and Williams (1982).

\section{Method}

Subjects. Sixteen male albino rats of Holizman descent, raised at Kenyon College and weighing 450-580 $\mathrm{g}$ at the time of testing, served as the intruder subjects. They were maintained on a 12:12 h reverse light:dark cycle and had food and water continuously available in their individual home cages. In addition, eight colonies of older rats of Holtzman descent were used for resident-intruder testing. In a previous study, the colonies had been found to have dominant male residents that displayed asymptotic levels of aggressive responses (e.g., lateral attacks and biting) during a series of 10 consecutive daily resident-intruder tests. Each of these aggressive colonies contained 1 female and 2 male rats that had been residents in a particular colony cage for a period of 60-70 days. The 
alpha males in the colonies ranged from 582 to $627 \mathrm{~g}$ at the time of intruder testing. The laboratory area and maintenance conditions for the aggressive colonies were the same as those used for the intruder subjects.

Apparatus. Inescapable shocks and restraint conditions were administered to intruder subjects in a Plexiglas tube, $28 \mathrm{~cm}$ in length and $7 \mathrm{~cm}$ in diameter. The rat's tail was taped to a thin Plexiglas rod that extended from the rear of the tube. Shocks were delivered from a Lafayette 82400 shock source through two electrodes attached to the rat's tail. All shock presentations were electronically controlled, and the shock tubes were located in a separate room in which white noise ( $75 \mathrm{~dB}$ SPL) was presented.

The eight aggressive colonies were each housed in $20 \times 50 \times 40 \mathrm{~cm}$ polypropylene tubs with stainless steel wire tops. The floors of the colony cages were covered with ground corn-cob mash as bedding material, which was changed periodically but not immediately prior to or during the colony-intruder tests.

Observations and recordings were made in a sound-attenuated experimental room. The animals could be seen through the wire covers of the colony cages. The colony area was illuminated by a 25 -W incandescent red bulb (G.E., $120 \mathrm{~V}$ ). The intruder animal was marked with a green marker (Magnum 44) to facilitate identification. Electronic event timers were used to record the duration of the various measures of defeat.

Procedure. The 16 rats later to be tested as intruder rats were assigned randomly to one of two conditions: preshocked (PS) or nonshocked (NS) groups. On the 1st day of the experiment, rats in Group PS were restrained in the tube and given $801-\mathrm{mA}, 5$-sec inescapable shocks presented on a variable-time schedule with a mean interval of $60 \mathrm{sec}$ and a range of 30-120 sec. The subjects in Group NS were merely restrained in the tube for $90 \mathrm{~min}$ and received no shocks.

On the following day, randomly determined pairs of subjects from each group were scheduled to be intruders in each of the eight aggressive colonies. Immediately before a resident-intruder test, the subjects in both groups were given five priming shocks via tail electrodes while being restrained in the tube. These shocks, which were used to reinstate the stress conditions for the preshocked subjects, were $5 \mathrm{sec}$ in duration and programmed to occur according to the same variable-time schedule that had been in effect for the preshacked rats on the previous day. Immediately following the priming shocks, the subjects were individually tested as intruders in one of the aggressive colonies. During these tests, the female rat in the colony was removed and food and water were not available. For half of the aggressive colonies, their first intruder was a preshocked subject and, $5 \mathrm{~h}$ later, their second intruder was a nonshocked control subject. The order was reversed for the remaining four colonies. Thus, each colony was tested with a rat from Group PS as well as with one from Group NS in a counterbalanced order with a 5-h intertest interval. During each 15-min test, an experienced observer of agonistic behavior recorded the total defeat time displayed by the intruder as well as the number of bites it received. The defeat time score obtained for each intruder was the total duration that the subject was engaged in either defensive rearing or lying on its back, often combined with freezing. Bites were recorded only if they elicited an audible response on the part of the intruder. Prior checks on the reliability of this scoring system, using videotapes of tests, have consistently yielded correlations higher than .90 .

\section{Results and Discussion}

All the alpha animals defeated the colony intruders, and no significant differences were observed in either the composite defeat-time scores or the number of bites received by intruders between the first and the second tests. Figure 1 presents the mean defeat time and the mean num-
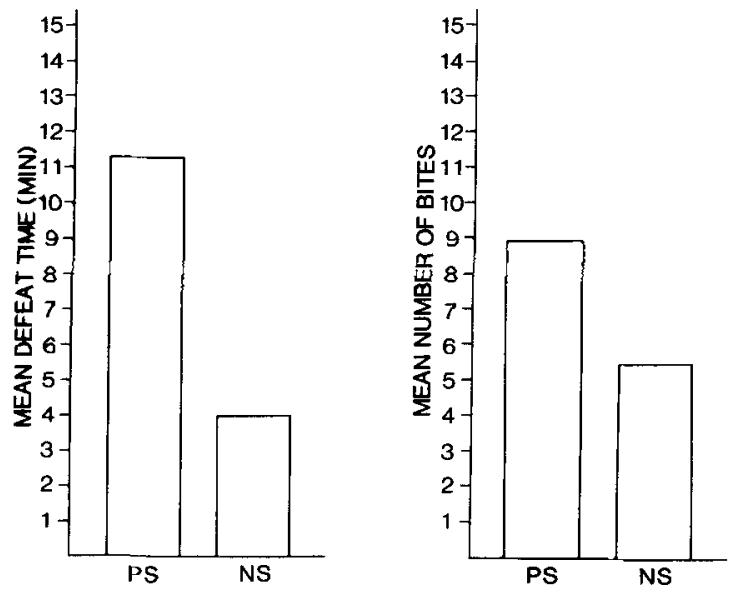

Figure 1. Mean defeat time (in minutes), or the total duration of defensive responses (left panel), and the mean number of bites received (right panel) by subjects tested as intruders in aggressive colonies. The two treatment conditions, given $24 \mathrm{~h}$ earlier, are inescapable preshock (Group PS) and restrained no shock (Group NS).

ber of bites received for the two groups of rats. Using colonies as a blocking variable, a correlated $t$ test revealed that the rats in Group PS spent more time displaying defeat behaviors than did the subjects in Groups $N S[r(7)=4.15$, $p<.01]$. The same type of analysis also indicated that the intruders in Group PS were bitten significantly more often by the alpha residents than were the rats in Group NS $[t(7)=2.39, p<.05]$. Within-group Spearman correlations for the defeat-time scores versus the number of bites showed that these measures were positively correlated for Group NS $[r(6)=.79, p<.01]$ and for Group PS $[r(6)=.59, p<.06]$.

These data provide clear evidence for the notion that inescapable shock makes a colony intruder even more defensive than it would have otherwise been when confronting an alpha resident animal. This finding is consistent with the results of Williams (1982), who found a decrement in aggression and an increase in defense by alpha animals that had been inescapably shocked. The fact that preshocked subjects were found to be more defensive and show submissive postures is also consistent with various ethological perspectives of the effects of pain and fear on responding (e.g., D. C. Blanchard, \& R. J. Blanchard, 1984b; Fanselow \& Lester, 1986). However, there are two related findings in this experiment which are more difficult to explain. First, why were preshocked animals bitten more often than nonshocked subjects; and second, why was there a positive correlation between defensive responding and the number of bites received by both groups of intruders? R. Blanchard and D. C. Blanchard (1981) and others have claimed that defensive behavior enables intruders or subordinate colony animals to defend themselves against alpha animals, which direct most of their bites to the intruder's back. If these investigators are correct, an inverse relationship should have been observed between defeat time and the number of bites the 
intruders received. Possibly one of the reasons why these two measures were found to be positively related in the present study was that the intruders were socially naive, having been housed in isolation. Furthermore, the dominant animals in the colonies were selected because of their previous display of asymptotic levels of aggression. These animals were very effective in rolling defeated intruders over and gaining access to their backs. Finally, they were also capable of provoking freezing intruders to flee, which, in turn, made it easy for them to bite the intruders' backs.

\section{EXPERIMENT 2}

Experiment 1 demonstrated that prior stress from inescapable shock potentiates defensive behaviors and the number of bites received by these rats when they are colony intruders $24 \mathrm{~h}$ later. Previous research, cited earlier in this paper, suggests that frequently the psychological dimension of controllability is a major factor in mediating the effects of stress. Thus, controllable, or escapable, aversive events have little or no consequence relative to uncontrollable ones. Particularly relevant to the present study were the findings reported by Williams (1982) that inescapable shock, in contrast to escapable and nonshocked treatments, results in decrements in aggression, increments in defense, and a reduction in the dominance status of alpha colony males.

The purpose of Experiment 2 was to determine whether shock controllability would also be a major factor in influencing the defeat behaviors that a previously isolated rat would show as a colony intruder. As noted earlier, this issue is an important one because there are no reported experiments that have demonstrated that inescapable, but not escapable, shock can augment defensive behaviors in previously naive intruders. The technique used to investigate this issue was the well-known triadic design, in which one group of subjects received shock escape training in a wheel-turn box and their yoked partners were given the same number and duration of inescapable shock presentations. A third, control, group of animals was restrained in the wheel box but not given shock. Finally, each of the animals was tested as an intruder in one of the aggressive colonies used in Experiment 1.

\section{Method}

Subjects. Twenty-four male albino rats of Holtzman descent, raised at Kenyon College and weighing 456-582 g, served as intruder subjects after receiving various stress treatments. We used the same eight colonies of older animals that had been used in Experiment 1 again to test for intruder defeat. As before, all colonies consisted of 1 female and 2 male rats, with one of the males being consistently aggressive toward intruders. All maintenance and laboratory conditions in this study were the same as those for Experiment 1.

Apparatus. Shock and restraint conditions were given in three identical wheel-turn boxes measuring $15.5 \times 12.0 \times 17.0 \mathrm{~cm}$. The side, front, and rear walls, as well as the top and floor of each box, were made of Plexiglas. A 64-cm-diam grooved Plexiglas wheel was located on the front wall and extended $1.5 \mathrm{~cm}$ into the cham- ber. The force required to move the wheel a quarter turn was approximately $30 \mathrm{~g}$. The rat's tail extended through a hole in the rear of each apparatus and was taped to a Plexiglas rod. Unscrambled shocks were delivered to the rat's tail via fixed electrodes from separate constant current Lafayette 82400 shock sources, which were continuously calibrated. Each wheel-turn box was housed in a soundattenuating cubicle equipped with a white-noise speaker, a houselight, and a ventilating fan. All treatment contingencies were electronically controlled, and the wheel-turn latencies made during escape training were automatically recorded via an electronic printout timer.

The housing of the eight colonies used during resident-intruder tests, as well as all of the various types of equipment involved in conducting these tests, were identical to those described for Experiment 1 .

Procedure. The 24 rats to later be used as intruders were assigned randomly to one of three conditions: escapable shock (ES), inescapable yoked shock (YS), or restrained no shock (R). On the initial day of the experiment, Group ES subjects received one shockescape training session in the wheel-turn box. The session consisted of 80 trials presented on a variable-time schedule, with a mean in terval of $60 \mathrm{sec}$ and a range of $30-120 \mathrm{sec}$. Shock terminated when the rat had completed a one-quarter turn of the wheel beyond $.8 \mathrm{sec}$ following the onset of shock. Wheel turns during the first $.8 \mathrm{sec}$ of shock were considered to be unlearned shock-elicited responses, which would not function as an effective coping response (see Maier \& Jackson, 1977, for a more complete description of the rationale for this procedure). All of these short-latency responses were programmed to have no consequence. Shock presentations, delivered via tail electrodes, terminated after $30 \mathrm{sec}$ if an escape response had not occurred. The shock intensity for all rats was begun at $.8 \mathrm{~mA}$ and then increased to $1.0 \mathrm{~mA}$ on Trial 20 , to $1.3 \mathrm{~mA}$ on Trial 40 , and to $1.6 \mathrm{~mA}$ on Trial 60 . This was done because previous studies (Williams, 1982, 1984) had revealed a deterioration of sustained wheel-turn performance over trials when a response-delay interval of shock termination was in effect and the shock intensity remained at $1.0 \mathrm{~mA}$.

The subjects in Group YS received the same number, duration, and intensity of shocks as did their Group ES partners. Shock began simultaneously for both subjects and terminated whenever the partner rat of Group YS made the appropriate wheel-turn response. Finally, the control subjects in Group $\mathbf{R}$ were restrained in the same wheel-turn boxes for a 90 -min period, but they were not given shock via the tail electrodes.

To determine the effects of the shock conditions on defeat, each subject was tested as an intruder in one of the eight aggressive colonies. Every aggressive colony encountered one intruder from each of the three groups. The order in which the subjects in each group were scheduled to be intruders was partially counterbalanced, and a 4-h interval separated the three tests in each colony. All experimental manipulations, observations, and recordings made during the colony-intruder tests were identical to those described for Experiment 1 .

\section{Results and Discussion}

All subjects in Group ES learned the wheel-turn escape response. The mean latency to respond during the last block of 10 trials was $2.46 \mathrm{sec}$, a value significantly shorter than the mean latency of $4.30 \mathrm{sec}$ during the first block of 10 trials $[t(7)=2.98, p<.01]$. Yoked subjects did not turn the wheel by the end of the training session.

Figure 2 shows the mean defeat time and the mean number of bites received by the rats in Groups ES, YS, and R. A randomized-blocks design ANOVA (with colonies as 

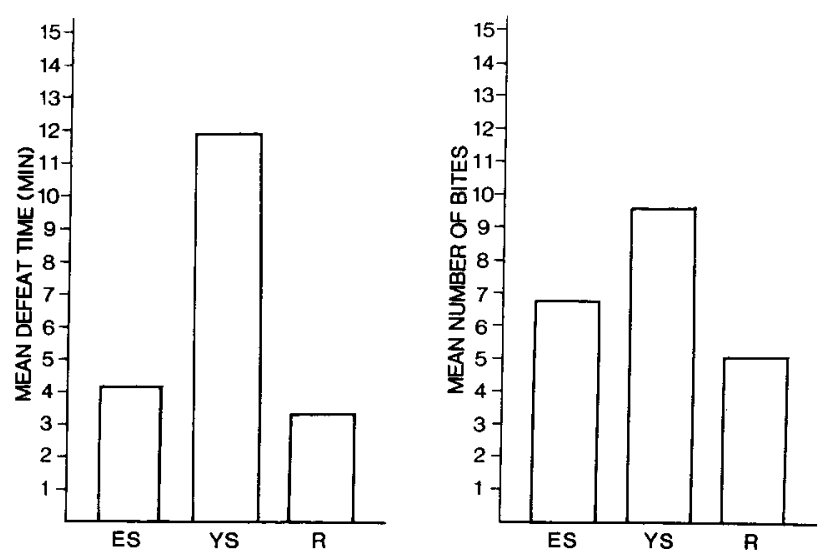

Figure 2. Mean defeat time (in minutes), or the total duration of defensive responses (left panel), and the mean number of bites received (right panel) by subjects tested as intruders in aggressive colonies. The three treatment conditions, given $24 \mathrm{~h}$ earlier, are wheel-turn escapable shock (Group ES), inescapable yoked shock (Group XS), and restrained no shock (Group R).

blocks and groups as the between-subjects factor) indicated that the groups differed significantly in their defeat time $[F(2,14)=23.90, p<.01]$. This overall analysis also showed that the amount of defeat provoked by the different colonies, across the treatment groups, did not differ significantly. Post hoc Newman-Keuls comparisons indicated that Group YS differed reliably $(p<.01)$ from the other two groups, which were not significantly different from one another. The number of bites received by the intruders for the various groups, which is also shown in Figure 2, appears to yield the same pattern of results as that found for intruder defeat time. Group YS intruders received more bites than the rats in either Group ES or Group R. However, a randomized-blocks ANOVA indicated that the differences between the groups were not statistically significant $(p<.15)$. Thus, it appears that defensive behaviors, which contributed to an intruder's defeat time, were more influenced by the manipulation of shock controllability than was the number of bites the animals received.

The above findings are the first to verify the notion that shock controllability vs. uncontrollability is an important factor in determining the extent to which animals will show defensive responding when they later confront dominant animals in an unfamiliar colony situation. Although all of the rats in each treatment condition showed defeat as intruders, only the animals receiving yoked-inescapable shock showed potentiated defeat. As was the case for the preshocked animals in Experiment 1, the rats given yoked shock in this experiment engaged in defensive behavior over three quarters of the time they were in the aggressive colonies. This is in contrast to the subjects in Groups ES and R, which both spent about a quarter of the test time displaying defeat behaviors. More importantly, these findings revealed that prior escapable-shock experience did not potentiate defeat since the defensive behavior shown by these animals was comparable to that shown by those in the nonshocked, restrained group. These results clearly parallel the numerous experiments that have demonstrated that motivational and emotional deficits occur only when stressors are uncontrollable, as opposed to when they are controllable (see reviews by Maier et al., 1983; Maier \& Seligman, 1976; Weiss et al., 1981).

\section{EXPERIMENT 3}

Another source of evidence indicating that stress controllability plays a critical role in determining interference or learned-helplessness reactions is the research on "immunization" and "therapy" effects. Seligman and Maier (1967) were the first investigators to report that dogs that initially received escape-avoidance training in a shuttlebox followed by inescapable shocks in a harness continued to escape effectively when returned to the same shuttlebox for further escape-avoidance testing. Likewise, Seligman, Rosellini, and Kozak (1975, Experiment 2) immunized rats by training them to jump onto an insertable ledge in a Skinner box. When these animals were exposed to inescapable shock and tested a day later for escape responding in the Skinner box, the performance of the immunized group was comparable to that of the nonshocked control group.

Since the immunization and test settings were identical in both of the above studies, these findings cannot be unequivocally attributed to the effects of response-outcome controllability per se. However, Williams and Maier (1977, Experiment 1) demonstrated a transituationimmunization effect by giving rats wheel-turn escape training (i.e., immunization) prior to inescapable shock in a restraining tube. Later, in a separate test environment, these rats showed enhanced FR-2 shuttlebox escape learning relative to a group of subjects that had been preshocked in the tubes but not given prior wheel-turn training. Using an identical design, Moye, Coon, Grau, and Maier (1981, Experiment 2) found that experience with escapable shock, prior to inescapable tube shock, partially immunized rats from showing long-term analgesic reaction to radiant heat applied to the tail. This study suggested that cross-stressor immunization is possible. More recently, Anisman, Irwin, Beauchamp, and Zacharko (1983) examined immunization effects on mice in the performance of water escape and shock tasks. Exposure to inescapable shock interfered with performance in both shock- and water-escape tasks, and such deficits were prevented when the subjects' training task was the same as the test task. However, when a cross-stressor paradigm was used, the results revealed that there was an asymmetrical immunization effect. Deficits of water-escape performance produced by inescapable shock were prevented by prior shock-escape training, whereas the deficits of shock-escape performance were not eliminated by prior water-escape training. Apparently, an immunization effect occurs either when the initial training and subsequent testing are conducted with the same task or when the ini- 
tial training and the uncontrollable stress session involve the same aversive stimulus.

One of the questions of interest in Experiment 3 was whether immunization experience with shock prevents the augmentation in defeat which we observed following uncontrollable shock in Experiments 1 and 2. More specifically, an immunized group of rats was given the following: (1) wheel-turn escape training, (2) a series of inescapable shocks in tubes $4 \mathrm{~h}$ later, and (3) a test for defeat $24 \mathrm{~h}$ later in an aggressive colony after receiving five priming shocks in the tube. A second objective of this experiment was to determine whether a therapy procedure could counteract the effect of shock-potentiated defeat. Williams and Maier (1977, Experiment 2) showed that inescapably shocked rats, which were given escape training with a chained-response sequence of leverpressing and jumping onto a platform, did not show deficits in acquiring a shuttling escape response. Using a similar design but a different therapy task, Moye et al. (1981, Experiment 1) demonstrated a transituational and crossstressor therapy effect using shock in the first two phases and later testing for tail-flick analgesia to radiant heat. As an extension of this area of research, Experiment 3 was designed to demonstrate whether a therapy effect, counteracting shock-potentiated defeat, would occur for colony intruders that had had controllable-shock experience after a session of uncontrollable shock. Thus, a therapy group of rats was given the following: (1) a series of inescapable tube shocks, (2) wheel-turn escape training $4 \mathrm{~h}$ later, and (3) a test for defeat $24 \mathrm{~h}$ later in an aggressive colony immediately after a series of priming shocks.

In addition to the immunization and therapy conditions, Experiment 3 included two other groups in order to provide important comparisons. A group of rats was given a restraint session in the wheel-turn box without shock and $4 \mathrm{~h}$ later inescapable shock in the tubes. Based on the results of Experiments 1 and 2, this group was expected to show an increment in defeat $24 \mathrm{~h}$ later during colony tests that were preceded by five priming shocks. In contrast, no potentiation of defeat was predicted to occur in a control group that was merely restrained in the tubes and wheel-turn boxes, without shock, for two sessions on one day and tested for defeat in a colony cage on the following day after exposure to five shocks. Previous research done by the present investigator (Williams \& Maier, 1977) found that exposure to inescapable shock in a wheel-turn box before exposure to inescapable shock in a restraining tube did not eliminate, but seemed to increase, the size of the helplessness effect in a subsequent shuttlebox learning task. Therefore, although such a double-session inescapable shock group might prove to be interesting, it was not considered necessary in order to demonstrate the ameliorative effects of immunization and therapy in the present experiment.

\section{Method}

Subjects. Thirty-two male albino rats of Holtzman descent, raised at Kenyon College and weighing 468-590 g, served as intruder sub- jects after having immunization, therapy, preshock, or restraint treatments. Because the eight colonies of animals used in the previous experiments continued to show asymptotic levels of aggression, they were also used to test for intruder defeat in the present study. All of the maintenance and laboratory conditions in this study were the same as those described for Experiment 1

Apparatus. The immunization and therapy sessions involving escapable shock took place in the wheel-turn boxes that were employed in Experiment 2. Inescapable shocks were given in the shock tubes described for Experiment 1. The shock sources, programming equipment, and the apparatus used during the resident-intruder test sessions were the same as those described for Experiment 1.

Procedure. The 32 animals to be used as intruder subjects were assigned randomly to one of four groups: escapable shock followed by inescapable shock (Group ES-IS), inescapable shock followed by escapable shock (Group IS-ES), restraint in the wheel-turn box followed by inescapable shock (Group R-IS), and restraint in the wheel-turn box followed by restraint in the shock tubes (Group R-R). All sessions with escapable shock occurred in the wheel-turn box, and all sessions with inescapable shock took place in the tubes.

On the first day of the experiment, half of the subjects (i.e., the first flight) in all four groups received the appropriate shock and/or restraining conditions during two sessions scheduled $4 \mathrm{~h}$ apart. The procedure used during escape training in the wheel-turn box was the same as that given to Group ES in Experiment 2, except that the latency of effective escape responses following the onset of the shock could have been as short as $0.0 \mathrm{sec}$ during the first 20 trials. Such reflexive responses were permitted in order to facilitate escape learning, particularly in the case of the preshocked therapy subjects. After Trial 20 , only wheel-turn responses with a latency of longer than $.8 \mathrm{sec}$ were effective in terminating shock. As noted previously, such responses were considered to be instrumental, nonreflexive behaviors that provided exposure to shock controllability. The procedure employed to provide inescapable tube shock was the same as that used with Group PS of Experiment 1. All escapable and inescapable shock sessions consisted of 60 trials. The restraint conditions were given for a comparable amount of time (i.e., $75 \mathrm{~min}$ ) in either the tube or the wheel-turn box, as indicated above. Since a similar degree of defeat was observed for Group NS of Experiment 1 and Group $R$ of Experiment 2, it was concluded that the possible stress produced by restraint in the tubes and the wheel-turn boxes was comparable. For this reason, it was not considered necessary to have an additional inescapably shocked control group that was matched to the therapy group with respect to the precise order of the restraint conditions and treatment environments.

Resident-intruder testing of the subjects was given $24 \mathrm{~h}$ after their session with inescapable shock in the tubes (or the second restraint session for Group R-R). The procedure used during these tests was similar to that described for Experiment 1. Each of the eight aggressive colonies encountered 2 new intruders from the four experimental groups during two successive colony-intruder tests, separated by a 5 -h intertest interval. On the next day, the remaining half, or second flight, of the experimental subjects were tested for two sessions in the wheel-turn boxes and tubes according to the procedure described above. Twenty-four hours later, they were each given a resident-intruder test in one of the aggressive colonies.

\section{Results and Discussion}

Both the immunized (i.e., Group ES-IS) and the therapy (i.e., Group IS-ES) groups received 60 trials of wheelturn escape training. In both of these groups, all the rats successfully learned to escape from shock in this apparatus. For Group ES-IS, the mean wheel-turn latency on the last block of 10 trials was $2.55 \mathrm{sec}$, which was significantly faster than the mean of $3.25 \mathrm{sec}$ for the first 
block of 10 trials $[t(7)=2.04, p<.05]$. Similarly, Group IS-ES had a mean wheel-turn latency of $1.21 \mathrm{sec}$ on the last block of trials, which differed significantly from a mean of $3.46 \mathrm{sec}$ during the first block of escape trials $[t(7)=4.28, p<.01]$. The shorter latency shown by both of these groups, relative to the wheel-turn performance of Group ES of Experiment 2, was due to the fact that latencies below $.8 \mathrm{sec}$ (i.e., reflexive responses) were effective as escape responses during the first 20 trials in this experiment.

Figure 3 presents the mean amount of defeat time the four groups of subjects showed as intruders as well as the number of times they were bitten during resident-intruder testing. It appears obvious that the group that had inescapable shock and no escape training (i.e., Group R-IS) displayed more defeat and received more bites than the rats in the other three groups. A randomized-blocks ANOVA, with colonies as the blocking variable, showed a significant effect between groups $[F(3,21)=20.59$, $p<.01]$ and between colonies $[F(7,21)=3.69, p<$ $.01]$ in terms of the defeat times or the total duration of defensive responses. Post hoc testing indicated that Group R-IS differed significantly $(p<.01)$ from the three other groups, which did not differ from one another. The same pattern of statistical results was obtained for analysis done on the number of bites that the intruders received. The overall ANOVA showed significant differences between groups $[F(3,21)=11.46, p<.01]$ and colonies $[F(7,21)$ $=4.15, p<.01]$; and post hoc tests indicated that the only significant differences were between Group R-IS and the other groups.

As was the case in Experiment 1, within-group Spearman correlations for defeat-time scores and the number of bites received by an intruder showed that these measures were positively related. Significant $r$ values were
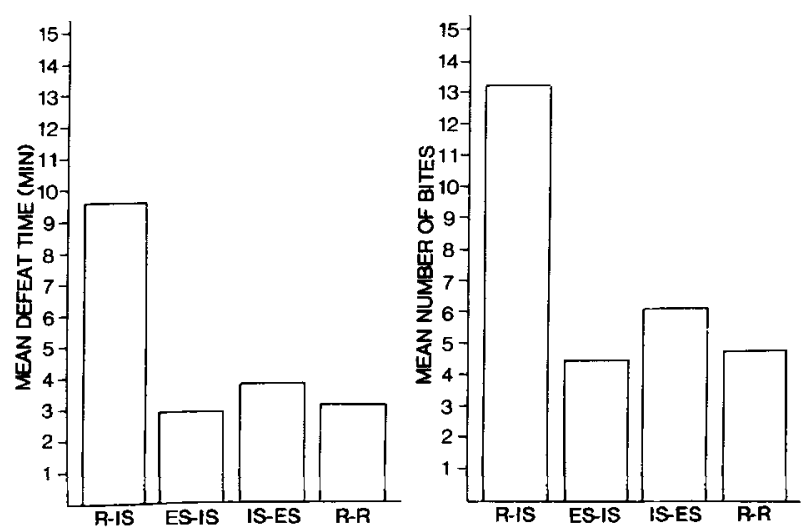

Figure 3. Mean defeat time (in minutes), or the total duration of defensive responses (left panel), and the mean number of bites received (right panel) by subjects tested as intruders in aggressive colonies. The four treatment conditions, given $24 \mathrm{~h}$ earlier, are restrained-inescapable shock (Group R-IS), escapable shock-inescapable shock (Group ES-IS), inescapable shock-escapable shock (Group IS-ES), and restrained-restrained (Group R-R). These consecutive treatment sessions were separated by a $4-h$ interval. found for Group R-IS [r(6) $=.70, p<.05]$, Group ES-IS $[r(6)=.74, p<.05]$, Group IS-ES $[r(6)=.66, p<$ $.05]$, and Group R-R $[r(6)=.64, p<.05]$. These data again refute the notion that the defensive behaviors made by an intruder were effective in reducing the number of bites such an animal received from an alpha colony resident.

The group differences, reported earlier, clearly show that the potentiation of defeat observed in preshocked intruders can be prevented and reversed by specific immunization and therapy procedures involving controllable shock. These findings also suggest that wheel-turn training is somewhat more effective as an immunization task than as a therapy procedure. However, the difference between these conditions (i.e., Group ES-IS and Group ISES) was not found to be statistically reliable. In many respects, the above findings are consistent with those reported in previous transituational immunization and therapy studies involving either behavioral measures of learning (Williams \& Maier, 1977) or sensitivity to pain (Moye et al., 1981). What is remarkable about these experiments is that the rats in the immunization and therapy conditions typically receive about twice as many shock presentations as do the subjects in the inescapable-shock condition (i.e., Group R-IS). Previous research has demonstrated that double exposure to inescapable shock has an incremental influence on the size of the helplessness effect (Williams \& Maier, 1977). In addition, the present findings confirm the results of Anisman et al. (1983), in that controllable shock counteracted the potential effects of uncontrollable shock, even when the test situation involved a different stressor. Whereas Anisman examined the cross-stressor immunization effects between shock controllability and water-escape during testing, this experiment documented the existence of both immunization and therapy effects between control over shock and subsequent resident-intruder testing.

\section{GENERAL DISCUSSION}

The first objective of the present experiments was to demonstrate whether prior stress would alter the degree of defeat, or defensive behavior, a rat displayed when tested a day later as an intruder in an aggressive colony of conspecifics. Relative to nonshocked animals, rats with exposure to inescapable shock showed more defeat and received more bites from dominant residents during intruder tests that were preceded by five priming shocks. The amount of time engaged in defeat and the number of bites received by an intruder were shown to be positively correlated within each group. The second objective of this research was to determine whether the controllability of shock as a stressor was a critical factor in producing augmented defeat during subsequent intruder tests. Shock controllability was, indeed, found to be important; inescapable, but not escapable, shock led to enhanced defeat relative to the amount by restrained nonshocked intruders. Finally, experience with escapable shock before or after 
inescapable shock eliminated (i.e., immunized or reverse therapeutized, respectively) the potentiated defeat reaction.

Prior studies have indicated that exposure to inescapable shock has disruptive effects on agonistic responses. For example, Williams (1982) reported that a deficit in aggression and an increment in defensive responding occur when dominant colony animals receive inescapable but not escapable shock. Thus, the present experiments extend these findings by demonstrating that socially isolated, naive intruders also display an increase in defense when tested in an aggressive colony after exposure to inescapable, as opposed to escapable, shock. These findings clearly suggest that one of the primary effects of inescapable shock is to alter an animal's species-typical behavior such that its dominant mode of responding becomes defensive and all other response systems are suppressed. This conceptualization of competing modes of behavior, or motivational systems, has been suggested by a number of investigators (e.g., Adams, 1980; D. C. Blanchard \& R. J. Blanchard, 1984a; Fanselow \& Baackes, 1982). Only recently, however, has it been demonstrated that the controllability versus uncontrollability of the stressor is critical in producing alterations in species-typical patterns of behavior (Williams , 1982, 1984). Finally, the present immunization and therapy experiments represent the first published data indicating that changes in species-typical responses, induced by inescapable shock, can be prevented and reversed.

A number of interpretations that have been proposed to account for the disruptive effects of inescapable shock do not explain the present results. For example, the leamed-inactivity or competing-response hypothesis (e.g., Anderson, Crowell, Cunningham, \& Lupo, 1979) requires that shock be given in the stress session and also in the test situation, but this was not the case in our experiments. Likewise, the effects of shock given $24 \mathrm{~h}$ previously during resident-intruder testing cannot be readily explained by the stress-motor-deficit hypothesis (Weiss, Glazer, \& Pohorecky, 1976), which was based on experimentation involving a very different set of parameters. Maier and Seligman (1976) have proposed a theory of learned helplessness to account for the wide range of behavioral and physiological disruptions produced by uncontrollable events. According to this view, exposure to inescapable, but not escapable, shock results in deficits in cognitive, motivational, and emotional or affective processes. The present observation that inescapable shock produces a potentiation in defeat when rats are subsequently tested as intruders is certainly consistent with their notion of shock-induced alterations in emotion (e.g., enhanced passivity). Furthermore, the successful demonstration of immunization and therapy effects against this hyperdefeat reaction to inescapable shock (Experiment 3 ) is also in agreement with the predictions of the learned helplessness theory. It is important to note that the procedures used in the present series of studies are very similar to those used by Maier and his colleagues to produce cognitive and activity deficits and stressinduced analgesia to nociceptive stimulation (Maier et al., 1983). This may lead one to speculate about the possibility that stress-induced analgesia and opioid mechanisms may mediate shock-potentiated defeat. As a matter of fact, Moye et al. (1981) have demonstrated immunization and therapy of long-term opioid analgesia in rats with procedures very similar to that used in Experiment 3 . However, Maier and others (e.g., Maier et al., 1983) claim that recent evidence indicates that no causal relationship can be inferred between opioid-mediated alterations in pain sensitivity and many of the behavioral disruptions attributed to learned helplessness (e.g., deficits in shuttlebox or Ymaze escape learning). Nevertheless, further research examining opioid manipulations may yield interesting results concerning shock-potentiated defeat.

A proposed interpretation of the present findings, which will be referred to as the "stress-coping-fear-defense" (SCFD) theory, assumes that the lack of coping or controllability over a stressor produces greater fear than does a controllable stressor. A number of earlier studies, using the conditioned emotional reaction (CER) procedure as an index of fear, provide support for this assumption in that rats that received signaled escapable shocks subsequently showed less suppression to the conditioned stimulus than did their yoked partners which received the same amount of inescapable shock (Brennan \& Riccio, 1975; Desiderato \& Newman, 1971; Osborne, Mattingly, Redmond, \& Osborne, 1975). More recently, Mineka, Cook, and S. Miller (1984, Experiments 1 and 2) reported that the defensive response of freezing was a more sensitive measure of fear than the operant CER index. They also found that signaled escapable shock produced less freezing than signaled inescapable shock when subjects were later tested for fear to the CS in a situation other than the one in which they had been conditioned. An additional finding of major theoretical importance was that their remaining studies confirmed an earlier prediction (Starr \& Mineka, 1977) that control per se was not necessary to produce the lower level of fear shown by the subjects in the escape group (Mineka et al., 1984, Experiments 3 and 4 ). These results indicated that yoked subjects receiving a feedback signal at the time their escape partners made a response showed a lower level of fear, comparable to that observed in the escape group and significantly less than that of a yoked group of subjects that did not have the feedback stimulus. These findings clearly indicate that the critical aspect of controllable shock is that the feedback of the escape response has fear-reducing effects. This research also emphasizes the importance of looking for classical conditioning mechanisms, as opposed to instrumental response-reinforcer contingencies, in accounting for the results of most learned helplessness studies.

However, unlike Mineka's studies, the procedure used in our experiments did not have an explicit conditioned stimulus present during the initial shock phase and again during the later resident-intruder test phase. Because the 
transfer of fear requires a common CS, we believe that a variety of inadvertently conditioned stimuli served as mediators. In addition to the fact that all of our subjects were primed in the shock tubes just before testing, we also assume that the presence of the experimenter and the pervasive odors of stressed conspecifics throughout the laboratory were responsible for the transfer of fear. Minor and LoLordo (1984) have previously suggested that such cues might be capable of functioning as mediators in previous learned helplessness experiments.

The second important assumption of the SCFD theory is that high levels of fear activate defense and submission systems (Adams, 1980), which in turn result in the display of species-typical defensive behaviors. Rats react to innate danger stimuli such as cats, dorsal tactile stimulation, and odors of stressed conspecifics with a variety of defensive behaviors (Fanselow \& Lester, 1986). Fanselow and Sigmundi (1986) have recently found that conditioned stimuli that have a history of association with nociceptive events (e.g., electric shock) can also cause an increase in defensive responses. With regard to the present experiments, the SCFD theory predicts that the presence of stress odors and other cues associated with a high level of fear during exposure to inescapable, but not escapable, shock results in an increase in defense when subjects are tested as intruders in aggressive colonies.

Although the SCFD formulation accounts for the results of Experiments 1 and 2, additional assumptions must be made in attempting to explain the ameliorative effects of the immunization and therapy procedures used in Experiment 3. Volpicelli, Ulm, Altenor, and Seligman (1983) have reported that escapable shock, relative to inescapable and no-shock conditions, prolonged responding during later testing with a series of inescapable shocks. A similar proactive interference effect, which is independent of the classical conditioning of fear, may have disrupted the learning that shocks were uncontrollable when our immunized subjects (i.e., Group ES-IS) were later given inescapable shock in the tubes. If this were the case, the fear conditioned to the transituational cues (e.g., stress odors), from the shock tubes to the colonies, would have been less, and subsequent defeat as a colony intruder would not have been enhanced. Similarly, retroactive interference with the recall of the inescapable-shock treatment by later wheel-turn escape training may have been the reason for the lack of potentiated defeat shown by the therapy subjects (e.g., Group IS-ES).

In conclusion, the SCFD theory was postulated to account for the differences in intruder defeat produced by escapable versus inescapable shock. Presumably, the increased defeat reaction resulting from inescapable shock is a function of a greater degree of fear conditioning to transituational cues. The feedback inherent in making the escape response for subjects with a controllable stressor serves to reduce fear by means of conditioned inhibition or relief from fear. In addition, the immunization and therapy effects that were found are assumed to be the result of the negative proactive and retroactive transfer effects concerning the learning about or recall of, respectively, the actual uncontrollability of inescapable shock. Although these findings and our theoretical formulations emphasize the interrelationships among shock controllability, the predictability of shock termination, conditioned stress cues, fear, and defensive behavior, further experimentation is necessary to examine the precise nature of these complex interactions.

\section{REFERENCES}

ADAms, D. B. (1980). Motivational systems of agonistic behavior in muroid rodents: A comparative review and neural model. Aggressive Behavior, 6, 295-346.

Anderson, D. C., Crowell, C. R., Cunningham, C. L., \& Lupo, J. V. (1979). Behavior during shock exposure as a determinant of subsequent interference with shuttle box escape-avoidance learning in the rat. Journal of Experimental Psychology: Animal Behavior Processes, 5, 243-257.

Anderson, D. C., Crowell, C. R., Wikoff, M. B., \& LUPo, J. V. (1980). Activity during prior shock determines subsequent shockelicited fighting in the rat. Animal Learning \& Behavior, 8, 664-672. ANiSMan, H., IRWin, J., BeAuchamp, C., \& ZaCharko, R. (1983). Cross-stressor immunization against the behavioral deficits introduced by uncontrollable shock. Behavioral Neuroscience, 97, 452-461.

anisman, H., Kokkinidis, L., Sklar, L. S. (1982). Contribution of neurochemical change to stress induced behavioral deficits. In $\mathbf{S}$. $J$. Cooper (Ed.), Theory in psychopharmacology (Vol. 1, pp. 65-102). London: Academic Press.

Blanchard, D. C., \& Blanchard, R. J. (1984a). Affect and aggression: An animal model applied to human behavior. In D. C. Blanchard \& R. J. Blanchard (Eds.), Advances in the study of aggression (Vol. 1, pp. 1-61). New York: Academic Press.

BLANCHARD, D. C., \& BlANCHARD, R. J. (1984b). Inadequacy of painaggression hypothesis revealed in naturalistic settings. Aggressive Behavior, 10, 33-46.

Blanchard, R. J., \& BlanchaRd, D. C. (1977). Aggressive behavior in the rat. Behavioral Biology, 21, 197-224.

Blanchard, R. J., \& Blanchard, D. C. (1981). The organization modelling of aggressive behavior. In P. F. Brain \& D. Benton (Eds.), The biology of aggression (pp. 529-561). Alphen aan den Rijn: Noordhoof/Sijthoff Press.

Blanchard, R. J., Kleinschmidt, C. K., Flannelly, K. J., \& BlanCHARD, D. C. (1984). Fear and aggression in the rat. Aggressive Behavior, 10, 309-315.

Blanchard, R. J., Takahashi, L. K., \& Blanchard, D. C. (1977). The development of intruder attack in colonies of laboratory rats. Animal Learning \& Behavior, 5, 365-369.

Bolles, R. C. (1970). Species-specific defensive reactions and avoidance learning. Psychological Review, 71, 32-48.

Bolles, R. C. (1972). Reinforcement, expectancy, and learning. Psychological Review, 79, 394-409.

Brennan, J. F., Riccio, D. C. (1975). Stimulus generalization of suppression in rats following aversively motivated instrumental or Pavlovian training. Joumal of Comparative \& Physiological Psychology, 88, 570-579.

Desiderato, O., \& Newman, A. (1971). Conditioned suppression produced in rats by tones paired with escapable or inescapable shock. Journal of Comparative \& Physiological Psychology, 77, 427-431.

Fanselow, M. S., \& BaAckes, M. P. (1982). Conditioned fear-induced opiate analgesia on the formalin test: Evidence for two aversive motivational systems. Learning \& Motivation, 13, 200-221.

FANselow, M. S., Lester, L. S. (1986). A functional behavioristic approach to aversively motivated behavior: Predatory imminence as a determinant of the topography of defensive behavior. In $\mathbf{R}$. C. Bolles \& M. D. Beecher (Eds.), Evolution and learning. Hillsdale, NJ: Erlbaum.

Fanselow, M. S., \& Sigmundi, R. A. (1986). A role for endogenous opioids in the defensive behavior of the rat. Paper presented at the 
meeting of the International Society of Research on Aggression in Chicago.

LESHNER, A. I. (1981). The role of hormones in the control of submissiveness. In P. F. Brain \& D. Benton (Eds.), Multidisciplinary approaches to aggression research (pp. 309-322). Amsterdam: Elsevier/North Holland Press.

Maier, S. F., Albin, R. W., \& Testa, T. J. (1973). Failure to learn to escape in rats previously exposed to inescapable shock depends on nature of escape response. Journal of Comparative \& Physiological Psychology, 85, 581-592.

Maier, S. F., ANDERSON, C., \& Lieberman, D. A. (1972). Influences of control of shock on subsequent shock-elicited aggression. Journal of Comparative \& Physiological Psychclogy, 81, 94-100.

Maler, S. F., Coon, D. J., MCDaniel, M. A., Jackson, R. L., \& GraU, J. (1979). The time course of learned helplessness, inactivity, and nociceptive deficits in rats. Learning \& Motivation, 10, 467-487.

Maier, S. F., Drugan, R., Grau, J. W., Hyson, R., Maclennan, A. J., Moye, T., Madden, J., \& Barchas, J. D. (1983). Learned helplessness, pain inhibition and the endogenous opiates. In M. D. Zeiler \& P. Harzem (Eds.), Advances in animal behavior (Vol. 3, pp. 275-323). New York: Wiley.

MAIER, S. F., \& JACKSON, R. L. (1977). The nature of the initial coping response and the learned helplessness effect. Animal Learning \& Behavior, 5, 407-414.

MAIER, S. F., \& JACKSON, R. L. (1979). Learned helplessness: All of us were right (and wrong): Inescapable shock has multiple effects. In G. Bower (Ed.), The psychology of learning and motivation (Vol. 3, pp. 155-218). New York: Academic Press.

Maier, S. F., \& Seligman, M. E. P. (1976). Learned helplessness: Theory and evidence. Joumal of Experimental Psychology: General, $105,3-46$.

Miller, N. E. (1948). Studies in fear as an acquirable drive: I. Fear as motivation and fear-reduction as reinforcement in the learning of new responses. Journal of Experimental Psychology, 38, 89-101.

MineKa, S., CoOK, M., \& Miller, S. (1984). Fear conditioned with escapable and inescapable shock: Effects of a feedback stimulus. Journal of Experimental Psychology: Animal Behavior Processes, 10, 307-323.

MinoR, J. R., \& LoLoRdo, V. M. (1984). Escape deficits following inescapable shock: The role of contextual odor. Journal of Experimental Psychology: Animal Behavior Processes, 10, 168-181.

Moye, T. B., Coon, D. J., Grau, J. W., Maier, S. F. (1981). Therapy and immunization of long-term analgesia in rats. Leaming \& Motivation, 12, 133-148.

Osborne, F., Mattingly, B., Redmond, W., \& Osborne, J. (1975). Factors affecting the measurement of classically conditioned fear in rats following exposure to escapable versus inescapable signalled shock. Journal of Experimental Psychology: Animal Behavior Processes, 1, 364-373.

Pinel, J. P. J., \& Treit, D. (1978). Burying as a defensive response in rats. Journal of Comparative \& Physiological Psychology, 92, 708-712.

RAPAPORT, P. M., MAIER, S. F. (1978). Inescapable shock and foodcompetition dominance in rats. Animal Learning \& Behavior, 6 , 160-165.

Seligman, M. E. P., \& MaIer, S. F.(1967). Failure to escape traumatic shock. Journal of Experimental Psychology, 74, 1-9.

Seligman, M. E. P., Rosellini, R. A., \& Kozak, M. (1975). Learned helplessness in the rat: Reversibility, time course, and immunization. Journal of Comparative \& Physiological Psychology, 85, 542-547.

STARR, M. D., \& MiNeKA, S. (1977). Determinants of fear over the course of avoidance learning. Learning \& Motivation, 8, 332-350.

Volpicelli, J. R., Ulm, R. R., Altenor, A., \& Seligman, M. E. P. (1983). Learned mastery in the rat. Leaming \& Motivation, 14, 204-222.

Weiss, J. M., Glazer, H. I., \& Pohorecky, L. A. (1976). Coping behaviors and neurochemical changes: An alternative explanation for the original "learned helplessness" experiments. In. G. Serban \& A. Kling (Eds.), Animal models in human psychobiology (pp. 141174). New York: Plenum Press.

Weiss, J., Goodman, P., Losito, B., Corrigan, S., Charry, J., \& BAILEY, W. (1981). Behavioral depression produced by an uncontrollable stressor: Relationship to norepinephrine, dopamine, and seratonin levels in various regions of rat brain. Brain Research Review, 3, 167-205.

WILLIAMS, J. L. (1982). Influence of shock controllability by dominant rats on subsequent attack and defensive behaviors toward colony intruders. Animal Leaming \& Behavior, 10, 305-313.

WILliams, J. L. (1984). Influence of postpartum shock controllability on subsequent maternal behavior in rats. Animal Learning \& Behavior. 12, 209-216.

Williams, J. L., Drugan, R. C., \& Maier, S. F. (1984). Exposure to uncontrollable stress alters withdrawal from morphine. Behavioral Neuroscience, 98, 836-846.

Williams, J. L., \& MaIER, S. F. (1977). Transituational immunization and therapy of learned helplessness in the rat. Journal of Experimental Psychology: Animal Behavior Processes, 3, 240-252.

(Manuscript received October 28, 1985; revision accepted for publication April 15, 1986.) 